\title{
Awareness on Various Surface Modifications of Implants Among Dental Students
}

\author{
B.Aishwarya Reddy ${ }^{1}$ and Dhanraj Ganapathy ${ }^{2}$ \\ ${ }^{1}$ Saveetha Dental College and Hospitals, Saveetha Institute of Medical \\ and Technical Sciences, Saveetha University, Chennai, 600077. \\ Professor and HOD, Department of Prosthodontics, Saveetha Dental College and Hospitals, Saveetha \\ Institute of Medical and Technical Sciences, Saveetha University, Chennai, 600077, India
}

\begin{abstract}
Implant surfaces are continuously being improved to achieve faster osseointegration and a stronger bone to implant interface. The adhesion and differentiation of osteoblastic cells are influenced by the surface properties of the dental implant. Surface properties include chemical composition, surface energy, roughness, and topography. In dental implants, surface roughness is often modified to modulate bone apposition. Surface roughness can be described as macro-, micro-, and nanometer-sized texture. Macro- and micrometer roughness facilitates mechanical anchorage to bone.The aim of this study is to estimate the awareness of various surface modifications of implants among dental students. A questionnaire with a set of 15 questions were prepared and an online survey was conducted among dental students using the survey planet. The sample size is 100. The results were analysed using SPSS software. From the study, $99 \%$ of the students were aware of a dental implant and $68 \%$ of the students have placed an implant. 75\% of the students think that sandblasted and acid etched implants have more success rate among the microtopography implants. According to the results, students were aware about the various surface modifications of implants and also most of the students have an experience of placing an implant.
\end{abstract}

KEY WORDS: ACID-ETCHED, IMPLANT,SURFACE MODIFICATIONS,SANDBLASTED,TITANIUM.

\section{INTRODUCTION}

Dental implant surface advancement techniques have been developing rapidly to facilitate osseointegration and bone formation on the implant surface and to enhance the predictability of accelerated implant therapy. Surface modifications have been proven effective on capitalizing the features of titanium that make it the material of choice in dental implantology. Some of these

\section{ARTICLE INFORMATION}

*Corresponding Author: dhanraj@saveetha.com

Received 14th June 2020 Accepted after revision 10th August 2020 Print ISSN: 0974-6455 Online ISSN: 2321-4007 CODEN: BBRCBA

Thomson Reuters ISI Web of Science Clarivate Analytics USA and Crossref Indexed Journal

\section{Clarivate}

NAAS Journal Score 2020 (4.31) SJIF: 2020 (7.728)

A Society of Science and Nature Publication,

Bhopal India 2020. All rights reserved.

Online Contents Available at: http//www.bbrc.in/

Doi: http://dx.doi.org/10.21786/bbrc/13.7/26 features include wettability, surface area, and osteogenic potential(Amarnath et al., 2011).

An implant is a medical device which is made from one or more biomaterials, that is intentionally placed in the body either totally or partially buried beneath an epithelial surface (Jayaswal, Dange and Khalikar, 2010) Osseointegration is the foundation of implant sciences and indefinite articles have been published on the various aspects of manufacturing the implants and on the clinical and laboratory phases of implants. The implant machining, surface, designing, surgical techniques and the peri-implant considerations have all progressed from infancy to the state of art and science and continue to evolve with each passing year. The surface characteristics at the micro or nanometre level, hydrophilicity, biochemical bonding and other features 
are few of the determiners which are responsible for the implant's success (Wennerberg et al., 1992). Osseointegration per se is not linked to certain defined surface characteristics, since a great number of different surfaces achieve osseointegration. However, the stronger or weaker bone responses may be related to the surface phenomenon. (Wennerberg and Albrektsson, 2010)

Osseointegration per se is not linked to certain defined surface characteristics, since a great number of different surfaces achieve osseointegration. However, the stronger or weaker bone responses may be related to the surface phenomenon. The bone implant interface can be controlled by the selection and modification of the biomaterial from which is made. These include morphological, physicochemical and biochemical methods (Amarnath et al., 2011).

The adhesion and differentiation of osteoblastic cells are influenced by the surface properties of the dental implant(EBSCOhost | 38012904 | Generalizations Regarding the Process and Phenomenon of Osseointegration. Part II. In Vitro Studies, no date) ('Osteoblast adhesion on biomaterials', 2000). Surface properties include chemical composition, surface energy, roughness, and topography. In dental implants, surface roughness is often modified to modulate bone apposition. Surface roughness can be described as macro-, micro-, and nanometer-sized texture(Jokstad, 2009). Macro- and micrometer roughness facilitates mechanical anchorage to bone. Nanometer roughness affects the adsorption of proteins and the adhesion of osteoblastic cells. It can modulate the rate of osseointegration(Turkyilmaz, 2011). A variety of surface treatments can be used to produce the desired surface topography(Brunette and Chehroudi, 1999). Commercially available implants vary in titanium composition and surface modifications having an understanding of these differences can help clinicians make an informed choice in implant selection for their patients(Nijhawan, Bali and Gupta, 2010).

Different surface modification techniques have been mainly used to improve the surface roughness and hydrophilicity. Some modified surface compositions could also contain bioactive substances. Implant morphology such as grooves, ridges, and tool marks can influence the interaction between the bone and the implant(Park et al., 2012). The implant morphology can also increase the overall surface area available for osseointegration. Rougher surfaces can stimulate attachment, differentiation, and proliferation of bone cells, thus increasing bone growth and mineralization. Rougher surfaces with an open structure have been shown to induce faster and more effective osseointegration. Unfortunately, this rougher surface substrate tends to accumulate bacteria (Olivares-Navarrete et al., 2012).

Previously our department has published extensive research on various aspects of prosthetic dentistry ('Evaluation of Corrosive Behavior of Four Nickelchromium Alloys in Artificial Saliva by Cyclic Polarization Test:An in vitro Study', 2017; Ganapathy,
Kannan and Venugopalan, 2017; Jain, 2017a, 2017b; Ranganathan, Ganapathy and Jain, 2017; Ariga et al., 2018; Gupta, Ariga and Deogade, 2018; Anbu et al., 2019; Ashok and Ganapathy, 2019; Duraisamy et al., 2019; Varghese, Ramesh and Veeraiyan, 2019), this vast research experience has inspired us to research about awareness on various surface modifications of implants among dental students.

\section{MATERIAL AND METHODS}

This is a questionnaire based study. A questionnaire with a set of 15 questions was prepared and circulated among the dental students.This was an online survey. The questionnaire was prepared using survey planet. 100 dental students have participated in this survey. The data was collected and tabulated. The data was imported to SPSS and the descriptive statistics with frequency analysis was done. The obtained data were represented graphically as bar charts.

Figure 1: Pie chart showing responses regarding the awareness on a dental implant in which $99 \%$ of them responded as "aware" and $1 \%$ responded as "not aware". Blue indicates "aware" and green indicates "not aware"

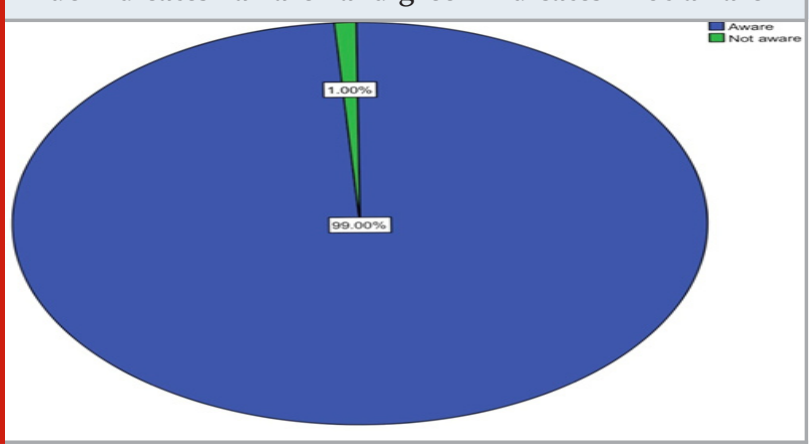

Figure 2- Pie chart showing responses regarding the placement of a dental implant in which $68 \%$ of them responded as "placed an implant" and 32\% of them responded that they have "not placed an implant". Blue indicates "placed an implant" and green indicates "not placed an implant"

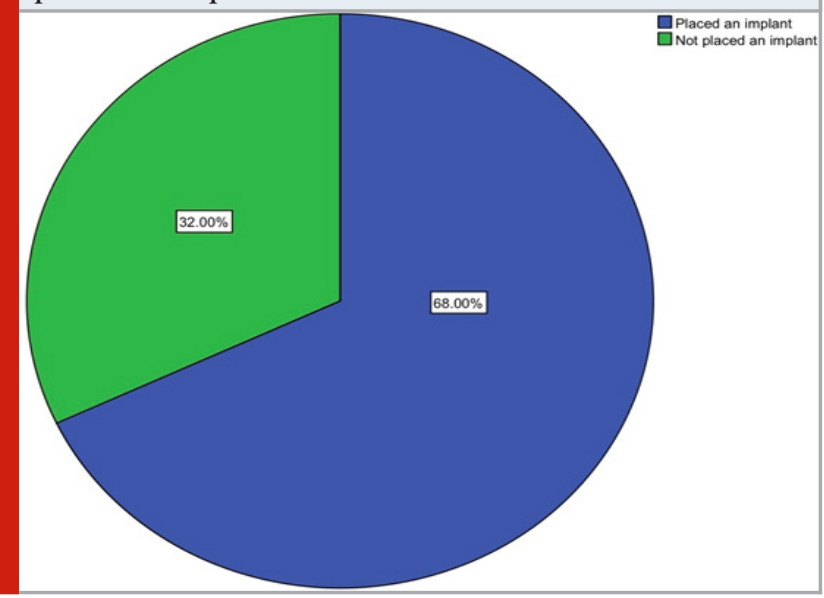




\section{RESULTS AND DISCUSSION}

A total of 100 dental students participated in this survey. When asked if the students were aware of a dental implant, 99\% of the students were aware about a dental implant and only $1 \%$ of the sample were not aware of a dental implant (Figure 1). The students were also asked if they have ever placed an implant and 68\% of the students have placed an implant and 32\% of the students have no experience in implant placement (Figure 2). When asked about the awareness on the various surface modifications of implants, 93\% of them were aware and only 7\% of them were not aware of the various surface modifications of the implant (Figure 3). A study given by Arati Sharma, et. al; 2019 (Sharma et al., 2019), found that a majority of the total students perceived themselves to be moderately well informed about dental implants (54.6\%). Awareness about dental implants is increasing among dental patients, which demands a higher level of competence for dental students. Awareness about dental implants is increasing among the general public and more and more patients are seeking information about dental implants.It is therefore useful to gauge the level of information about dental implants among dental students. All undergraduate dental students require basic knowledge about dental implant therapy so that they can educate and guide patients to undergo implant therapy whenever appropriate (Kohli et al., 2015).

Figure 3: Pie chart showing responses regarding the awareness of the various surface modifications of a dental implant in which $93 \%$ of them responded as "aware" and $7 \%$ of them responded that they are "not aware". Blue indicates "aware" and green indicates "not aware"

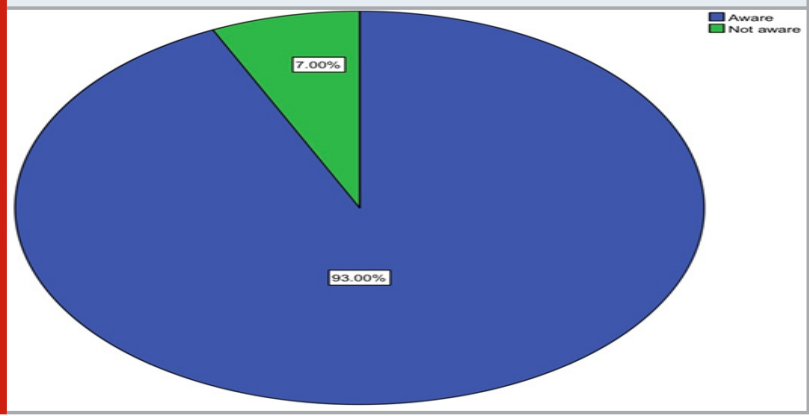

Figure 4: Pie chart showing responses regarding the awareness of dental implant topography in which $70 \%$ of them responded as "aware" and 30\% of them responded that they are "not aware". Blue indicates "aware" and green indicates "not aware"

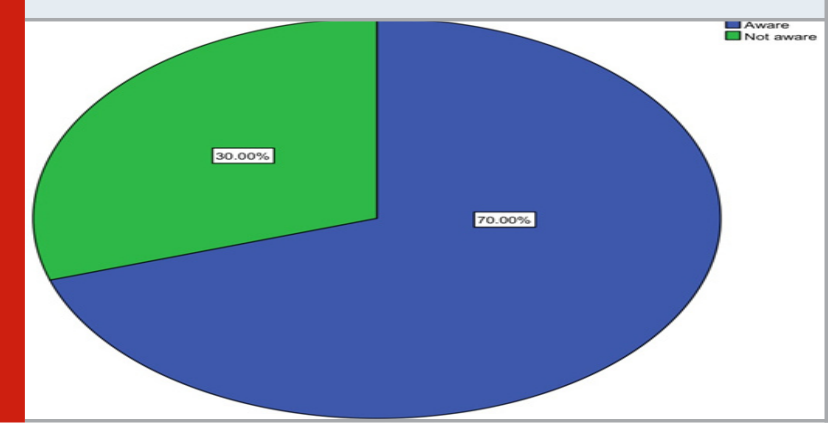

The students were asked if they were aware of dental implant topography, in which $70 \%$ of the students were aware of implant topography and 30\% of them were not aware (Figure 4). Implant surface topography refers to macroscopic and microscopic features of the implant surface. Surface topography of an implant can be designed by making porous and/or by coating the implant surface with other suitable materials to increase bone-implant contact since the anatomic surface of bone cannot be controlled. A number of surface treatments are available to create controlled roughness on the surface of the implants(Kohles et al., 2004).

The students were asked if they were aware of each and every type of implant modification, where 65\% of them were aware and 35\% of them were not aware of the gritblasted, acid-etched and neutralised implants (Figure 5). $52 \%$ of them were aware of discrete crystalline deposition implants and 48\% of them were not aware (Figure 6 ). 65\% of the students were aware and 35\% were not aware of laser ablation implants ( Figure 7). 53\% of the students were aware and $47 \%$ of them were not aware of anodic oxidation implant (Figure 8). 64\% of the students were aware of hydrophilic implants and 36\% of them were not aware( Figure 9).Titanium oxide blasted and acid-etched implants (Figure 10) and sandblasted acid etched implants(Figure 11) show the highest prevalence of awareness among the students with 82\%. A study given by Ramaglia L et.al; 2011 (Ramaglia et al., 2011), states that sandblasted and titanium oxide blasted with acid etching is the most common surface modification and it is therefore likely that specific surface properties of sandblasted-acid-etched titanium implants may modulate the biological behavior of osteoblasts during bone tissue healing.

Figure 5: Pie chart showing responses regarding the awareness of grit-blasted,acid-etched and neutralised implants in which 65\% of them responded as "aware" and $35 \%$ of them responded that they are "not aware". Blue indicates "aware" and green indicates "not aware"

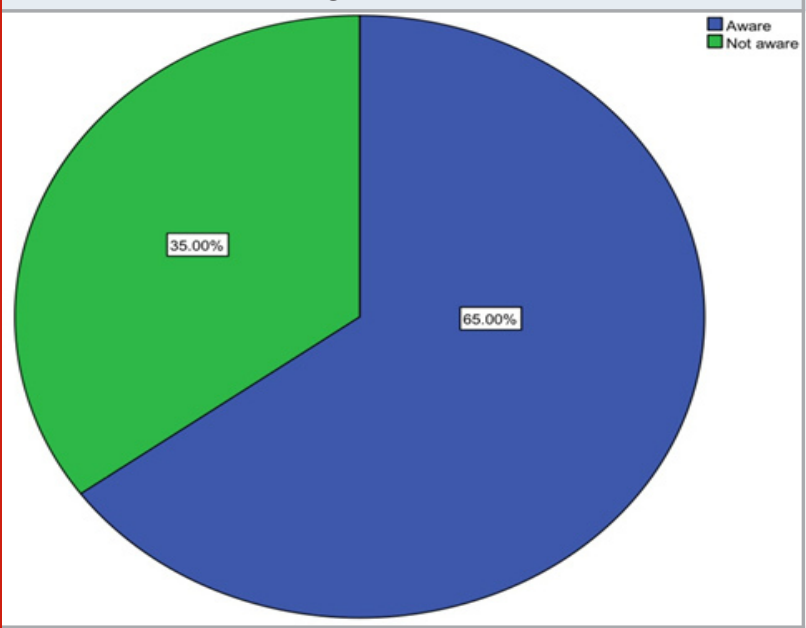


Figure 6: Pie chart showing responses regarding the awareness of discrete crystalline deposition implants in which 52\% of them responded as "aware" and 48\% of them responded that they are "not aware". Blue indicates "aware" and green indicates "not aware"

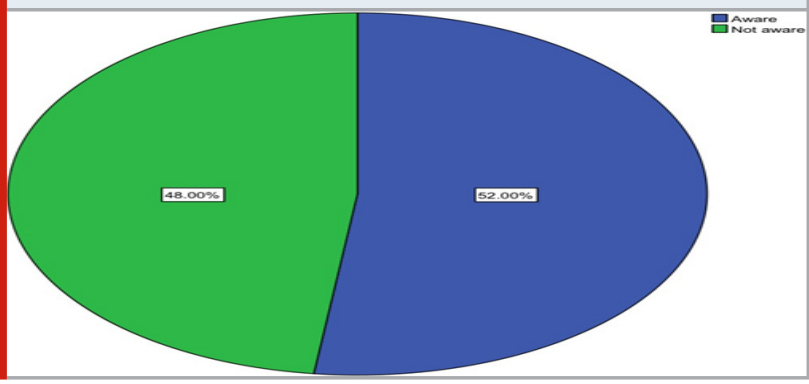

Figure 7: Pie chart showing responses regarding the awareness of laser ablation implants in which 65\% of them responded as "aware" and 35\% of them responded that they are "not aware". Blue indicates "aware" and green indicates "not aware"

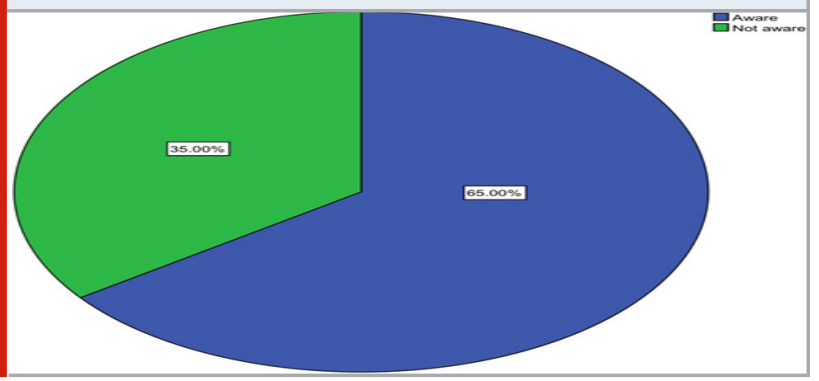

Figure 8: Pie chart showing responses regarding the awareness of anodic oxidation implants in which 53\% of them responded as "aware" and 47\% of them responded that they are "not aware". Blue indicates "aware" and green indicates "not aware"

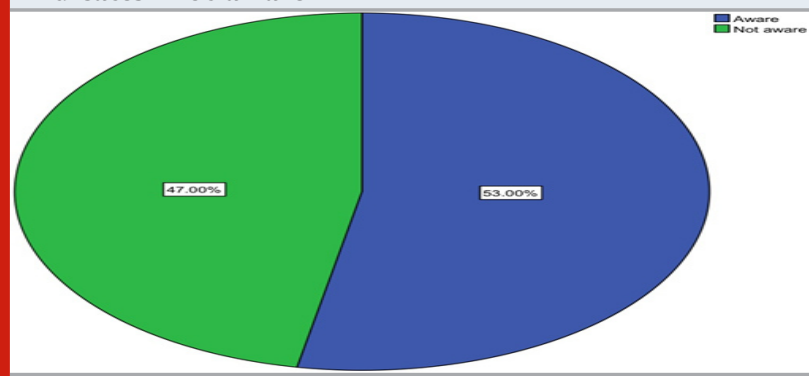

Figure 9: Pie chart showing responses regarding the awareness of Hydrophilic implants in which 64\% of them responded as "aware" and 36\% of them responded that they are "not aware". Blue indicates "aware" and green indicates "not aware".

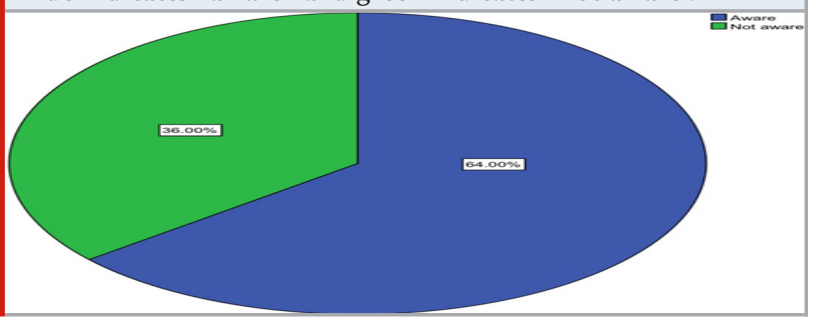

151
Figure 10: Pie chart showing responses regarding the awareness of Titanium oxide blasted and acid-etched implants in which $82 \%$ of them responded as "aware" and $18 \%$ of them responded that they are "not aware". Blue indicates "aware" and green indicates "not aware"

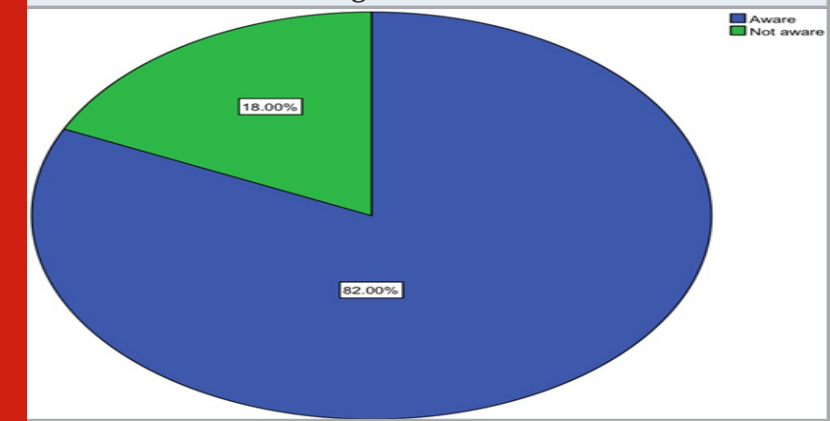

Figure 11: Pie chart showing responses regarding the awareness of Sandblasted and acid-etched implants in which $82 \%$ of them responded as "aware" and $18 \%$ of them responded that they are "not aware". Blue indicates "aware" and green indicates "not aware"

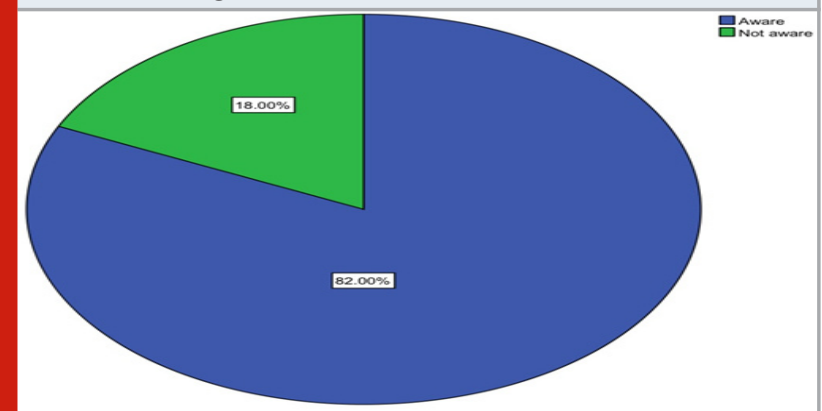

Figure 12: Pie chart showing responses regarding the opinion of more success rate in microtopography implants in which 75\% of them responded as "sandblasted and acid etched implants" and 25\% of them responded that they are "grit blasted, acid etched and neutralised implants". Blue indicates "sandblasted and acid etched implants" and green indicates "grit blasted, acid etched and neutralised implants"

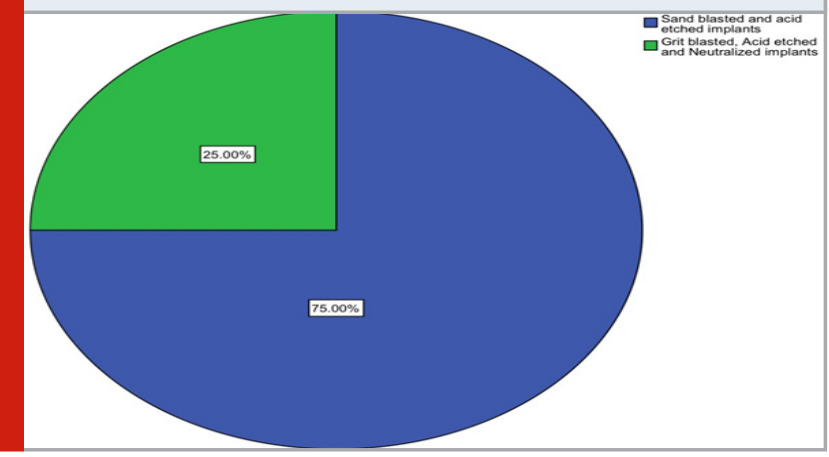

When asked about the implant with the highest success rate in microtopography implants, 75\% of the students think sandblasted and acid etched implants have more success rate and 25\% of the students think that grit 
blasted, acid etched and neutralized implants have more success rate (Figure 12). The students were also asked about the success rate of nanotopography implants, where $49 \%$ of them think Titanium oxide blasted and acid etched implants have more success rate among nanotopography implants followed by Laser ablation with 28\%, Discrete crystalline deposition with $11 \%$, Anodic oxidation implants with 9\% and hydrophilic implants with 3\% (Figure13).

Figure 13: Pie chart showing responses regarding the opinion on more success rate in nanotopography implants in which $49 \%$ of them responded as "Titanium oxide blasted and acid etched implants", 28\% responded as " laser ablation implants", 11\% responded as "discrete crystalline deposition implants", 9\% with "anodic oxidation implants" and 3\% with "hydrophilic implants". Violet indicates Titanium oxide blasted and acid etched implants, green indicates laser ablation implants, blue discrete crystalline deposition implants indicates, yellow indicates anodic oxidation implants and red indicates hydrophilic implants

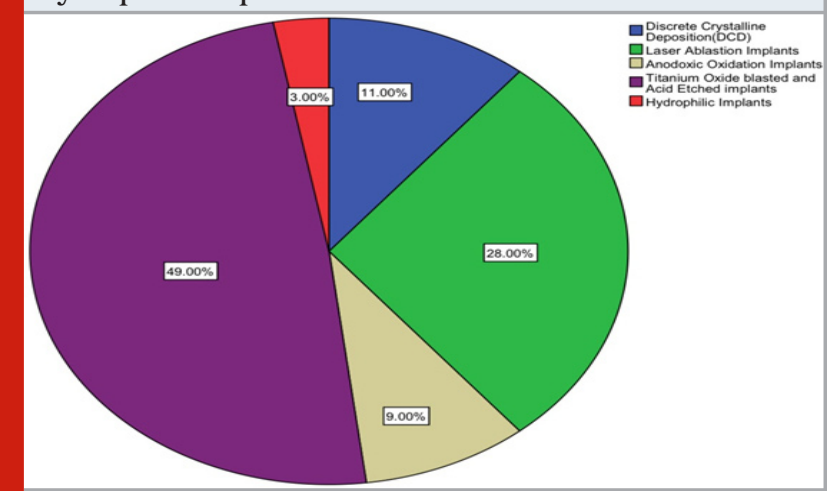

CONCLUSION

Within the limits of the study, the dental students were aware of the various surface modifications of an implant. More awareness should be created among the students and the patients are also well aware of new techniques in the field of dentistry. Similar studies on large populations should be done in order to get the relevant results. This study will act as a guide to understand the awareness of various surface modifications of dental implants among dental students.

\section{ACKNOWLEDGEMENTS}

All the authors have equally contributed to this study.

Conflict of Interest: None to declare

\section{REFERENCES}

Amarnath, G. S. et al. (2011) 'Biomaterials for Dental Implants: An Overview’, International Journal of Oral Implantology \& Clinical Research, pp. 13-24. doi: 10.5005/jp-journals-10012-1030.

Anbu, R. T. et al. (2019) 'Comparison of the Efficacy of Three Different Bone Regeneration Materials: An Animal Study', European journal of dentistry, 13(1), pp. 22-28.

Ariga, P. et al. (2018) 'Determination of Correlation of Width of Maxillary Anterior Teeth using Extraoral and Intraoral Factors in Indian Population: A Systematic Review', World Journal of Dentistry, 9(1), pp. 68-75.

Ashok, V. and Ganapathy, D. (2019) 'A geometrical method to classify face forms', Journal of oral biology and craniofacial research, 9(3), pp. 232-235.

Brunette, D. M. and Chehroudi, B. (1999) 'The Effects of the Surface Topography of Micromachined Titanium Substrata on Cell Behavior in Vitro and in Vivo', Journal of Biomechanical Engineering, pp. 49-57. doi: 10.1115/1.2798042.

Duraisamy, R. et al. (2019) 'Compatibility of Nonoriginal Abutments With Implants: Evaluation of Microgap at the Implant-Abutment Interface, With Original and Nonoriginal Abutments', Implant dentistry, 28(3), pp. 289-295.

EBSCOhost | 38012904 | Generalizations Regarding the Process and Phenomenon of Osseointegration. Part II. In Vitro Studies (no date). Available at: https://bit. ly/394kXTB (Accessed: 1 July 2020).

Evaluation of Corrosive Behavior of Four Nickelchromium Alloys in Artificial Saliva by Cyclic Polarization Test:An in vitro Study' (2017) World Journal of Dentistry, 8(6), pp. 477-482.

Ganapathy, D. M., Kannan, A. and Venugopalan, S. (2017) 'Effect of Coated Surfaces influencing Screw Loosening in Implants: A Systematic Review and Meta-analysis', World Journal of Dentistry, 8(6), pp. 496-502.

Gupta, P., Ariga, P. and Deogade, S. C. (2018) 'Effect of Monopoly-coating Agent on the Surface Roughness of a Tissue Conditioner Subjected to Cleansing and Disinfection: A Contact Profilometric Study', Contemporary clinical dentistry, 9(Suppl 1), pp. S122S126.

Jain, A. R. (2017a) 'Clinical and Functional Outcomes of Implant Prostheses in Fibula Free Flaps', World Journal of Dentistry, 8(3), pp. 171-176.

Jain, A. R. (2017b) 'Prevalence of Partial Edentulousness and Treatment needs in Rural Population of South India', World Journal of Dentistry, 8(3), pp. 213-217.

Jayaswal, G. P., Dange, S. P. and Khalikar, A. N. (2010) 'Bioceramic in dental implants: A review', Journal of Indian Prosthodontic Society, 10(1), pp. 8-12.

Jokstad, A. (2009) Osseointegration and Dental Implants. John Wiley \& Sons.

Kohles, S. S. et al. (2004) 'Direct assessment of profilometric roughness variability from typical implant surface types', The International journal of oral \& 
maxillofacial implants, 19(4), pp. 510-516.

Kohli, S. et al. (2015) 'Patients awareness and attitude towards dental implants', Indian Journal of Dentistry, p. 167. doi: 10.4103/0975-962x.168518.

Nijhawan, S., Bali, P. and Gupta, V. (2010) 'An Overview of the Effect of Topographic Surface Modifications of Endosteal Implants An Overview of the Effect of Topographic Surface Modifications of Endosteal Implants', International Journal of Oral Implantology and Clinical Research, pp. 77-82. doi: 10.5005/jpjournals-10012-1012.

Olivares-Navarrete, R. et al. (2012) 'Osteoblast maturation and new bone formation in response to titanium implant surface features are reduced with age', Journal of Bone and Mineral Research, pp. 1773-1783. doi: 10.1002/jbmr.1628.

Osteoblast adhesion on biomaterials' (2000) Biomaterials. Elsevier, 21(7), pp. 667-681.

Park, J. H. et al. (2012) 'Use of polyelectrolyte thin films to modulate Osteoblast response to microstructured titanium surfaces', Biomaterials, pp. 5267-5277. doi: 10.1016/j.biomaterials.2012.03.074.

Ramaglia, L. et al. (2011) 'Sandblasted-acid-etched titanium surface influences in vitro the biologicalbehavior of SaOS-2 human osteoblast-like cells', Dental materials journal. jstage.jst.go.jp, advpub, pp. 11031001221103100122.

Ranganathan, H., Ganapathy, D. M. and Jain, A. R. (2017) 'Cervical and Incisal Marginal Discrepancy in Ceramic Laminate Veneering Materials: A SEM Analysis', Contemporary clinical dentistry, 8(2), pp. 272-278.

Sharma, A. et al. (2019) 'Knowledge and perception about dental implants among undergraduate dental students', BDJ open, 5, p. 1.

Turkyilmaz, I. (2011) Implant Dentistry: A Rapidly Evolving Practice. BoD - Books on Demand.

Varghese, S. S., Ramesh, A. and Veeraiyan, D. N. (2019) 'Blended Module-Based Teaching in Biostatistics and Research Methodology: A Retrospective Study with Postgraduate Dental Students', Journal of dental education, 83(4), pp. 445-450.

Wennerberg, A. et al. (1992) 'An optical threedimensional technique for topographical descriptions of surgical implants', Journal of Biomedical Engineering, pp. 412-418. doi: 10.1016/0141-5425(92)90087-2.

Wennerberg, A. and Albrektsson, T. (2010) 'On implant surfaces: a review of current knowledge and opinions', The International journal of oral \&t maxillofacial implants, 25(1), pp. 63-74. 